\title{
Enrichments of gene replacement events by Agrobacterium- mediated recombinase-mediated cassette exchange
}

\author{
Hiroyasu Ebinuma $\cdot$ Katsuhiko Nakahama \\ Kazuya Nanto
}

Received: 3 February 2014/ Accepted: 22 August 2014/Published online: 15 February 2015

(C) The Author(s) 2015. This article is published with open access at Springerlink.com

\begin{abstract}
We report recombinase-mediated cassette exchange (RMCE), which can permit integration of transgenes into pre-defined chromosomal loci with no co-expressed marker gene by using Agrobacteriummediated transformation. Transgenic tobacco plants which have a single copy of negative marker genes $(\operatorname{cod} A)$ at target loci in heterozygous and homozygous conditions were used for gene exchange by the RMCE method. By negative selection, we were able to obtain five heterozygous and four homozygous transgenic plants in which the genes were exchanged from 64 leaf segments of heterozygous and homozygous target plants, respectively. Except for one transgenic plant with an extra copy, the other eight plants had only a single copy of marker-free transgenes, and no footprint of random integrated copies was detected in half of the eight plants. The RMCE re-transformation frequencies were calculated as $6.25 \%$ per explant and were
\end{abstract}

H. Ebinuma ( $\square)$

Faculty of Textile Science and Technology, Shinshu

University, 3-15-1, Tokida, Ueda, Nagano 386-8567,

Japan

e-mail: ebynuma@shinshu-u.ac.jp

K. Nakahama $\cdot$ K. Nanto

Agri-Biotechnology Research Laboratory, Nippon Paper Industries Co. Ltd., 5-21-1, Oji, Kita-ku, Tokyo 114-0002, Japan

e-mail: k.nakahama@nipponpapergroup.com

K. Nanto

e-mail: 0950168@nipponpapergroup.com approximately the same as the average percentage of intact single-copy transformation events for standard tobacco Agrobacterium-mediated transformation.

Keywords RMCE $\cdot$ Gene replacement $\cdot$ Negative selection
Abbreviations
RMCE Recombinase-mediated cassette exchange
SDI Site-directed integration
5-FC 5-Fluorocytosine
5-FU 5-Fluorouracil
CTAB Cetyltrimethylammonium bromide

\section{Introduction}

In current transformation methods, variable numbers of transgenes together with co-expressed marker genes are randomly inserted into the plant genome. Transgene instability and variation in expression levels are frequently caused by complex integration structure. A large amount of DNA and RNA analysis is required to identify transgenic plants with a single copy of transgenes with a stable expression level for analysis of gene functions and biotechnology risk assessments. Recent advances in recombinase-mediated cassette exchange (RMCE) have enabled enhanced tag-andexchange strategies for single-copy high-throughput 
targeted integration (Turan et al. 2011, 2013). We have developed Agrobacterium-mediated transformation methods which enable us to introduce a markerfree transgene into pre-defined chromosomal loci by RMCE.

RMCE is a tool box for replacing a genomic target cassette with a compatible donor cassette. The target and donor cassettes are each flanked by two oppositely oriented recognition sites and recombinase catalyzes double-crossover between the two recognition sites for replacement. Agrobacterium introduces a small amount of linear singlestranded T-DNA, which is not a suitable substrate for recombinase, into the plant nucleus (Tinland et al. 1994). Before T-DNA integration, a transferred single-stranded T-DNA is converted into a double-stranded DNA (Singer et al. 2012). Agrobacterium-mediated methods are efficient for targeted transformation by RMCE (Nanto et al. 2005; Louwerse et al. 2007). A large difference in expression levels of exchanged genes is detected between four different chromosomal target sites (Nanto et al. 2009; Ebinuma et al. 2012). The concept of removing a marker gene from targeted transgenic plants is demonstrated by repeated transformation (Srivastava and Ow 2004; Nanto and Ebinuma 2008). Through multiple rounds of RMCE using biolistic-mediated transformation, groups of six transgenes are stacked onto the same target sites (Li et al. 2009, 2010).

Recently, designed sequence-specific nucleases (ZENs, TALENs, CRISPR/Cas) have been demonstrated to enable not only site-specific mutagenesis and integration but also gene replacement (Tzfira et al. 2012; Belhaj et al. 2013; Endo and Toki 2014). Gene targeting is generated by induction of double-strand breaks at specific genome loci and DNA repairs via non-homologous end joining (NHEJ) or homologous recombination (HR). Gene replacement events are reproduced via $H R$, and co-delivery of the gene of interest as a template for HR with nucleases to specific genome loci remains a problem in plants. We reported that Agrobacterium could efficiently co-deliver the gene of interest to target genome loci with recombinases and reproduce gene replacement events (Nanto et al. 2005). In this report, we demonstrate the enrichment protocols of gene replacement events by Agrobacterium-mediated RMCE and discuss the common problems of HR- and RMCEmediated gene replacements.

\section{Results and discussion}

Molecular strategy

We designed the site-directed integration (SDI) vector system for producing marker-free targeted transgenic plants. We used the site-specific recombination system $(\mathrm{R} / R s)$ consisting of the recombinase $(\mathrm{R})$ and its recognition sites $(R s)$, which is derived from the plasmid pSR1 of Zygosaccharomyces rouxi (Araki et al. 1992). The SDI vector system consists of a target vector to introduce a target cassette and an exchange vector to reintroduce an exchange cassette for gene replacement (Fig. 1). The target vector pTSspsRScodN has a target cassette containing target genes (npt and $\operatorname{cod} A$ ), which are flanked by two oppositely oriented $R s$. The $\operatorname{cod} A$ gene codes for cytosine deaminase, which converts 5-fluorocytosine (5-FC) to 5-fluorouracil (5-FU). Since 5-FU is toxic to plant cells, a transgenic plant with a $\operatorname{codA}$ gene is blighted on medium containing 5-FC (Schlaman and Hooykaas 1997). The exchange vector p2nd30 has an exchange cassette containing a desired gene (luc) flanked by two oppositely oriented $R s$. Moreover, two directly oriented $R s$ flank the ipt, $R$, and luc genes (excision cassette), and the $g f p$ gene is located outside the excision cassette. The ipt gene is derived from the Ti-plasmid of Agrobacterium tumefaciens and codes for isopentenyl transferase, which catalyzes cytokinin synthesis (Akiyoshi et al. 1984).

Target line

We introduced the target vector pTSspsRScodN into tobacco plants and the T0 transgenic line $(\operatorname{cod} 23)$ was self-crossed to produce T1 transgenic lines $(\operatorname{cod} 23 \mathrm{~A}$, B) with a single copy of a target cassette in heterozygous and homozygous conditions. To confirm the copy number of target genes of $\operatorname{cod} 23 \mathrm{~A}$ and B lines, we isolated large-scale DNA from T0 transgenic plants $(\operatorname{cod} 23)$ and digested it with three restriction enzymes for Southern analysis. The predicted 9.0-, 6.0- or 11.0-kb fragment was hybridized with the P1 probe (codA) by HindIII, EcoRV or EcoRI digestion, respectively. The predicted 8.0- or 13.0-kb fragment was hybridized with the $\mathrm{P} 2$ probe by EcoRV or HindIII digestion, respectively, and the 
Fig. 1 Molecular strategy for producing marker-free targeted transgenic plants by RMCE. When the exchange vector $\mathrm{p} 2 \mathrm{nd} 30$ is introduced into target plants $(\operatorname{cod} 23 \mathrm{~A}$, B), recombinase catalyzes double-crossover between the two $R s$ to replace the target cassette with the exchange cassette. As a result, the transgenic plants (Type I, Type II) that have an exchange cassette at the target locus are produced. The diagram shows the integrated T-DNA region containing a target cassette of target plants $(\operatorname{cod} 23 \mathrm{~A}, \mathrm{~B})$, the T-DNA region of exchange vector $\mathrm{p} 2 \mathrm{nd} 30$, the integrated T-DNA region containing an exchange cassette of transgenic plants (Type I, Type II), the position of probes $(\mathrm{P} 1, \mathrm{P} 2$, P3, P4, P5) for Southern analysis, the size $(\mathrm{kb})$ of DNA fragments detected by the probes, restriction enzyme sites (E: EcoRI; EV: EcoRV; H: HindIII) and the DNA regions amplified with PCR primers (SPR3-Luc8a, Luc3-SPL3, SPR3-Luc3, Luc8a-SPL3). $\operatorname{cod} A$ cytosine deaminase gene, $n p t$ neomycin phosphotransferase gene, gfp green-fluorescent transferase gene,

$R$ recombinase gene, luc firefly luciferase gene, $R s$ recognition site, $R B$ and $L B$ right and left border sequences of a T-DNA protein gene, ipt isopentenyl

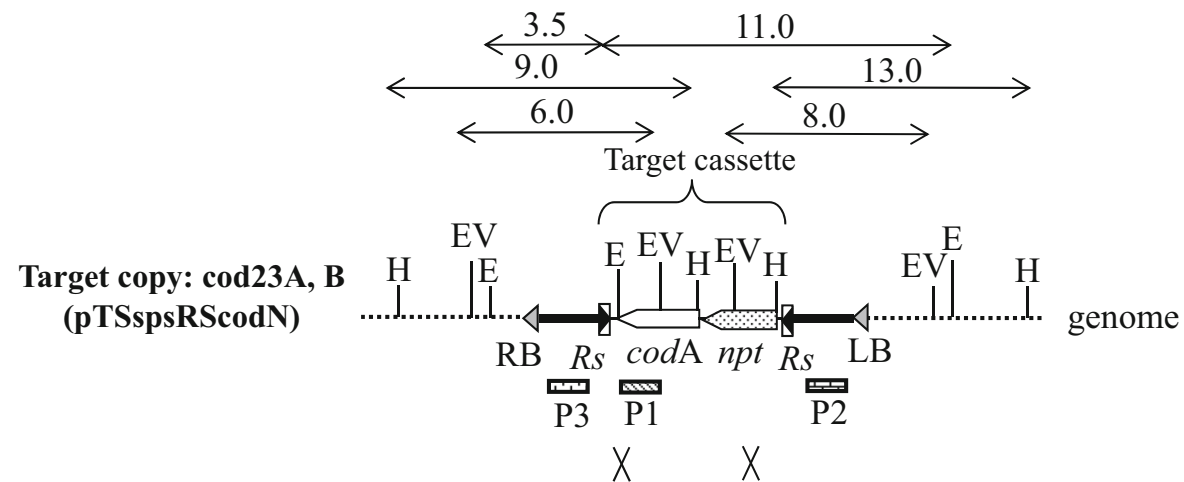
Exchange vector p2nd30

Exchange cassette

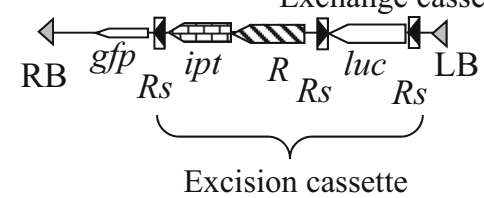

Exchanged copy

(Type I)

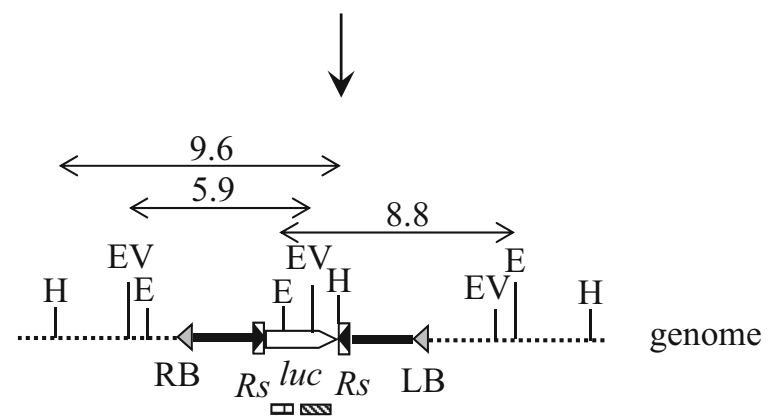

$$
\text { P5 P4 }
$$

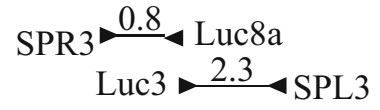

Exchanged copy

(Type II)

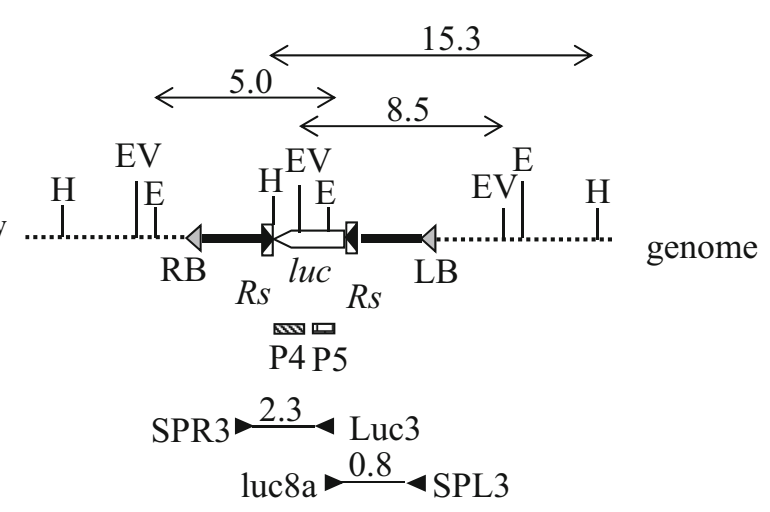

predicted $3.5-\mathrm{kb}$ fragment with the $\mathrm{P} 3$ probe by EcoRI digestion (Figs. 1, 2). These results indicate only the presence of a single copy of target genes in $\operatorname{cod} 23$ lines.

\section{Re-transformation}

We infected 64 leaf segments from each of two target lines ( $\operatorname{cod} 23 \mathrm{~A}, \mathrm{~B})$ with A. tumefaciens containing the 
Fig. 2 Southern analysis of T0 target plant $(\operatorname{cod} 23)$ and transgenic plants in which the genes were exchanged from two target lines $(\operatorname{cod} 23 \mathrm{~A}, \mathrm{~B})$. Genomic DNA was digested with three restriction enzymes (E: EcoRI; EV: EcoRV; H:

HindIII) and hybridized with five probes (P1, P2, P3, $\mathrm{P} 4, \mathrm{P} 5)$, respectively

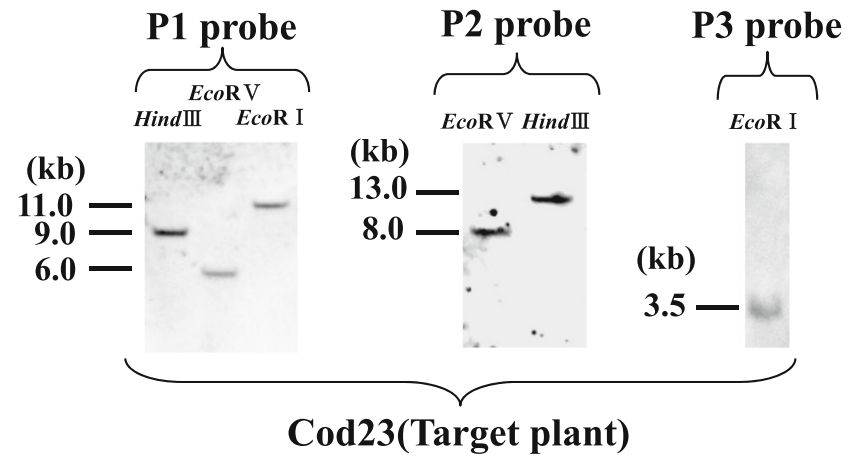

P4 probe

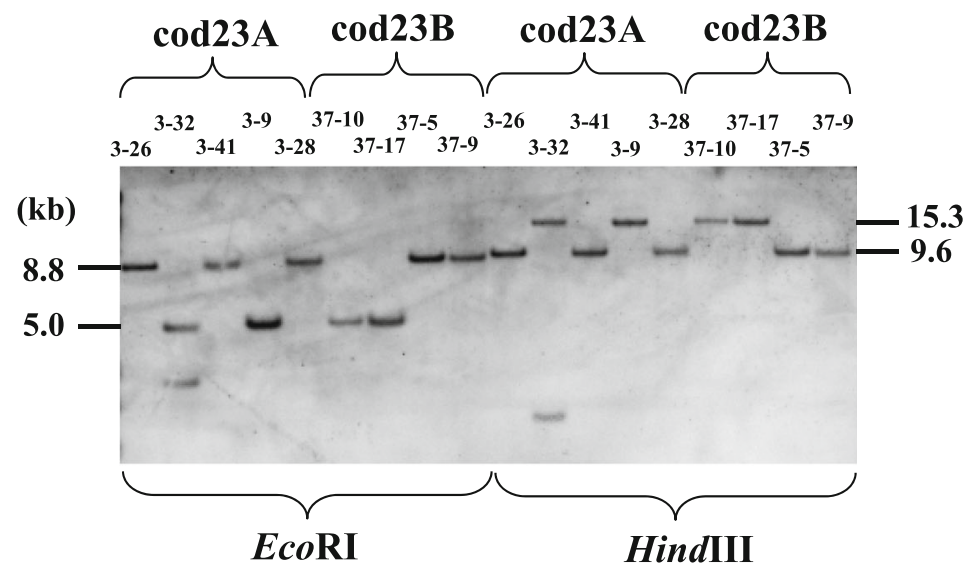

P5 probe

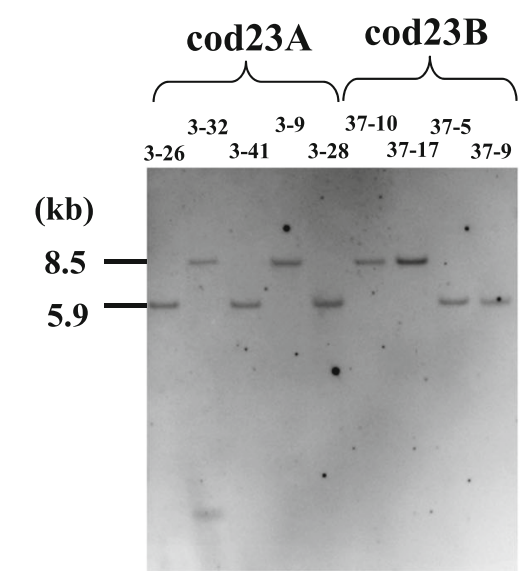

EcoRV exchange vector $\mathrm{p} 2 \mathrm{nd} 30$. First, we placed the infected leaf segments on the medium containing only plant hormones to induce callus formation. Two weeks after infection, we transferred these explants to the medium containing plant hormones and 5-FC for negative selection. After 1 month of cultivation, we separated 60 5-FC-resistant calluses from leaf segments and subcultured them on the same medium. After 1 month 
of cultivation, we separated less than two shoots from each callus and transferred them to hormone-free medium for rooting. Overall, about 6 months after infection, we obtained 40 normally rooted plants of independent callus lines from the cod23A line and 23 plants from the cod23B line.

\section{DNA analysis}

To detect precise integration of the exchange cassette into the target locus, we isolated DNA from these normally rooted plants and subjected it to PCR analysis. When the target cassette was replaced by the exchange cassette, both the predicted 0.8- and 2.3-kb fragments were amplified with the primer pairs SPR3-Luc8a and Luc3-SPL3 (Type I), or the predicted 2.3- and 0.8-kb fragments were amplified with the primer pairs SPR3Luc3 and Luc8a-SPL3 (Type II) (Fig. 1). In 40 normally rooted plants from the cod23A line, the expected exchange fragments were amplified in five plants, of which three were Type I and two were Type II. In 23 normally rooted plants from the $\operatorname{cod} 23 \mathrm{~B}$ line, the expected exchange fragments were amplified in four plants, of which two were Type I and two were Type II. Furthermore, we investigated the presence of the $n p t$, ipt or $R$ genes in these nine plants by PCR analysis. We detected the luc gene in all of the plants, but not the $n p t$, $i p t$ or $R$ genes. We identified five plants from the $\operatorname{cod} 23 \mathrm{~A}$ line and four plants from the cod23B line as transgenic plants in which the genes were exchanged (Table 1).

To determine the structure of the exchanged copy at the target locus, we isolated large-scale DNA from nine transgenic plants and digested it with three restriction enzymes for Southern analysis. In Type I transgenic plants, the predicted 8.8 - or $9.6-\mathrm{kb}$ fragment was hybridized with the $\mathrm{P} 4$ probe (luc) by EcoRI or HindIII digestion, respectively, and the predicted 5.9-kb fragment with the P5 probe (luc) by EcoRV digestion. In Type II transgenic plants, the predicted 5.0- or 15.3-kb fragment was hybridized with the P4 probe (luc) by EcoRI or HindIII digestion, respectively, and the predicted $8.5-\mathrm{kb}$ fragment with the P5 probe (luc) by EcoRV digestion (Fig. 1). In all of the nine transgenic plants, the predicted exchange fragments were detected and in only one plant (3-32) was an extra fragment detected (Fig. 2). These results indicate that eight plants from the codA and B lines have only a single copy of the precisely exchanged cassette containing a desired gene (luc).
Table 1 Transformation efficiency of target lines $(\operatorname{cod} 23 \mathrm{~A}, \mathrm{~B})$ with the exchange vector $\mathrm{p} 2 \mathrm{nd} 30$

\begin{tabular}{lll}
\hline Target lines & $\operatorname{cod} 23 \mathrm{~A}$ & $\operatorname{cod} 23 \mathrm{~B}$ \\
\hline Explants $^{\mathrm{a}}$ & 64 & 64 \\
Calluses $^{\mathrm{b}}$ & 60 & 60 \\
Rooted shoots $^{\mathrm{c}}$ & 40 & 23 \\
Transgenic plants $^{\mathrm{d}}$ & $5(4)^{\mathrm{e}}$ & $4(4)^{\mathrm{e}}$ \\
Exchange frequency $^{\mathrm{f}}(\%)$ & 6.25 & 6.25 \\
\hline
\end{tabular}

${ }^{a}$ Number of leaf segments infected with Agrobacterium

b Number of calluses cultured on the medium containing 5-FC

c Number of normally rooted shoots

d Number of transgenic plants which had an exchanged copy

e Number of transgenic plants which did not have any extra copies

${ }^{\mathrm{f}}$ Percentage of transgenic plants which had only an exchanged copy

Furthermore, we investigated by PCR analysis the presence of the $g f p$ gene in eight transgenic plants in which the genes were exchanged to confirm the footprints of randomly integrated copies on the plant genome. As the $g f p$ gene was located outside the excision cassette flanked by two directly oriented $R s$ (Fig. 1), after the removal of randomly integrated copies by recombination, the $g f p$ gene remained on the chromosome. We detected the $g f p$ gene in one transgenic plant (3-26) from the $\operatorname{cod} 23 \mathrm{~A}$ line and three $(37-10,37-5,37-9)$ from the cod23B line (data not shown). These results indicate that recombinase efficiently catalyzes the removal of randomly integrated copies and also the direct replacement of an exchange cassette with a target cassette at target loci, not through random integration.

\section{Progeny test}

We backcrossed the wild tobacco plant SR1 with eight transgenic plants in which the genes were exchanged to investigate the segregation of an exchanged cassette containing a desired gene $(l u c)$. We obtained normal seeds from all transgenic plants and subjected T1 seeds to progeny tests by PCR analysis with the primer pairs Luc3-Luc8a. The progeny of four transgenic plants from the cod23A line were PCR-positive for the luc gene in the predicted segregation ratio (1:1). All of the progeny of four transgenic plants from the $\operatorname{cod} 23 \mathrm{~B}$ 
line were PCR-positive. These results indicate that the transgenic plants from the $\operatorname{cod} 23 \mathrm{~A}$ or $\mathrm{B}$ lines have a single exchanged copy in heterozygous or homozygous condition, respectively, and the exchanged copy is stably transmitted to the progeny.

Expression of the luciferase (luc) gene

We subjected the progeny of eight transgenic plants in which the genes were exchanged from the $\operatorname{cod} 23 \mathrm{~A}$ and $\mathrm{B}$ lines to a quantitative luciferase assay. We analyzed five T1 plants from each transgenic plant and calculated the average luciferase activity. We detected high levels of luciferase activity in each of the transgenic plants. We report the production of eight control transgenic plants which contain a single copy of the transgenes, the hpt and luc genes, between two oppositely oriented $R s$ sites, by standard transformation methods (Nanto et al. 2009). Compared to exchanged lines, these lines clearly showed a high variability of luciferase activity.

\section{Agrobacterium-mediated RMCE}

As we used Agrobacterium to re-introduce desired genes into target lines, we expected that most of them would be randomly integrated into the plant genome of target lines and that the probability with which recombinase exchanged a target gene for a desired gene at pre-defined genomic loci would be far too low. In this report, therefore, we employed several strategies with the aim of addressing these issues. The desired genes, together with the ipt and recombinase genes, are flanked by two directly oriented recognition sites (Fig. 1). Recombinase removes randomly integrated copies from the genome and the ipt gene is used as a negative marker to select transgenic plants without such copies. Moreover, the $\operatorname{cod} A$ gene is located at the target loci and used as a negative marker to select targeted transgenic plants without it. We combine these strategies to enrich targeted events and to make screening procedures more simple and effective.

We located a $g f p$ gene outside two directly oriented recognition sites, which flanked the desired genes, together with the ipt and recombinase genes (Fig. 1) in order to detect a footprint of their random integration into the genome. By PCR analysis, we detected no $g f p$ gene in two of 13 targeted transgenic plants (Nanto et al. 2005), in one of two plants (Nanto and Ebinuma 2008), in five of 20 plants (Nanto et al. 2009) and in four of eight plants (this report). Such high percentages of targeted ones with no footprint indicate that a desired gene is directly exchanged with a target gene at pre-defined chromosomal loci by RMCE, not through random integration. It has been reported that a transferred single-stranded T-DNA is converted into double-stranded DNA before T-DNA integration (Singer et al. 2012). A double-stranded T-DNA intermediate is a good substrate for RMCE events by the SDI vector system.

\section{Promotion of RMCE events}

We expected that two factors would play an important role in the efficiency of targeting events. One is the promotion effect by the ipt gene (Akiyoshi et al. 1984). The desired and recombinase genes are introduced together with the ipt gene into target lines. The ipt gene would increase the frequency of gene targeting events during transformation since cytokinin induces callus formation and proliferates selectively transgenic cells where the desired and recombinase genes are introduced. The other is the high paring ability of recognition sites. We use the site-specific recombination system $(\mathrm{R} / R s)$ derived from the plasmid pSR1 of Zygosaccharomyces rouxii (Araki et al. 1992). Their plasmids contain a pair of the 959-bp inverted repeats, within a 58-bp region on which recombinase catalyzes site-specific recombination. This region contains a 7-bp spacer sequence flanked by two 12-bp inverted repeat sequences. One of these two repeats is flanked by four additional direct repeats with 4-bp spacer sequences. By PCR, we amplified a 400-bp recognition site containing all these repeats from the 959-bp inverted repeats. In the bacteriophage P1 Cre/lox system, a recognition site in which two 13-bp inverted repeat sequences flank an 8-bp spacer sequence is widely used (Wang et al. 2011). As the paring ability of recognition sites depends on size and structure, a 400-bp sequence may promote the alignment of a desired gene with a target gene and increase the exchange frequency.

\section{HR- and RMCE-mediated gene replacements}

Unlike NHEJ-mediated site-specific mutagenesis and deletion, HR-mediated gene replacement needs codelivery of the gene of interest as a template for HR 
with nucleases to specific genome sites. Gene replacement events using ZFNs (Wright et al. 2005; Cai et al. 2009; Townsend et al. 2009; Shukla et al. 2009; de Pater et al. 2009, 2013; Qi et al. 2013) and TALENs (Zhang et al. 2013) were detected but transgenic plants were obtained in only a few studies (Shukla et al. 2009; de Pater et al. 2009, 2013) because the technical demand is high. Most studies co-delivered the template DNA and nuclease expression constructs to cell suspensions or protoplasts by direct DNA transformation methods. They make it possible to introduce a large quantity of DNA into large populations of plant cells and identify the gene replacement events without large-scale selection, whereas conventional Agrobacterium-mediated transformation methods, which are commonly used for a wide variety of crops, introduce a small quantity of single-strand T-DNA into small populations of plant cells and integrate it randomly into the plant genome. In Arabidopsis, transgenic plants with gene replacement events via the floral dip transformation method were obtained with frequencies of $1.0 \times 10^{-3}$ (de Pater et al. 2009) and $3.1 \times$ $10^{-3}$ (de Pater et al. 2013) per transformation event, and the authors employed gene-specific selection regimes in which HR-mediated modifications of pre-inserted or endogenous genes confer a selectable phenotype. The positive-negative selection regime can be used for any target gene but relies on the generation of very large number of transformation events. Thus, development of selection regimes and enrichment protocols is needed for screening of the cells including the HR-mediated gene replacement events from the non-transgenic cells, and the transgenic cells including the NHEJ-mediated mutagenesis events or the randomly integrated events. In this study, we employ the "hit-and-run" cassette strategy of the MAT vector system (Ebinuma et al. 2005) which enables enrichments of gene replacement events by removal of randomly integrated copies. The "hit-and-run" cassette has the ipt and recombinase genes which are flanked by two directly oriented recognition sites. The ipt gene promotes the increase in transgenic cells and recombinase removes randomly integrated copies from the genome. The timing of expression of recombinase can be tightly harmonized with the co-delivery of the gene of interest. As a result, RMCE-mediated gene replacement events are concentrated. The "hit-and-run" cassette strategy is simple and effective and applicable to HR-mediated gene replacement.

\section{Materials and methods}

Plasmid constructs

Plasmids were constructed using standard recombinant techniques (Maniatis et al. 1982). The binary vector plasmid pTSsps contained an Sse8387I site between $S m a \mathrm{I}$ and $S a c \mathrm{I}$ at a specific sequence. The pCAmp plasmid contained an amp gene flanked by two oppositely oriented $R s$ sequences (Nanto et al. 2005). The HindIII fragment of the nos promoter-nptnos terminator and the HindIII-EcoRI fragment of the CaMV35S promoter-codA-nos terminator were ligated into the HindIII site and the HindIII-EcoRI sites of pCAmp to produce pCAmpcodN. pCAmpcodN was reconstructed to produce $\mathrm{pCcodN}$ by removing the amp gene. The Sse8387I fragment of pCcodN was ligated into the Sse8387I site of pTSsps to produce the target vector pTSspsRScodN (Fig. 1).

The HindIII-SmaI fragment of the Rs sequence was amplified by PCR and ligated into the HindIII-SmaI site of pTL7 to produce pTLRS(sma). The HindIII fragment of the CaMV35S promoter-gfp-nos terminator, the KpnI fragment of the $R b c-3 \mathrm{~B}$ promoter-ipt, and the EcoRI fragment of the CaMV35S promoter- $R$-nos terminator were ligated into the HindIII, KpnI, and EcoRI sites of pTLRS(sma) to produce pTLRSRubipt35R. The fragment of the nos promoter-luc-nos terminator was ligated into the KpnI sites of pCAmp to produce pCAmpluc. pCAmpluc was reconstructed to produce pCluc by removing the amp gene. The Sse8387I fragment of pCluc was ligated into the Sse8387I site of pTLRSRubipt35R to produce the exchange vector p2nd30 (Fig. 1).

\section{Plant transformation}

The binary vector plasmid pTSspsRScodN was introduced into A. tumefaciens strain LBA4404 by electroporation (Nagel et al. 1990). Leaves of in vitro clones of Nicotiana tabacum cv. SR1 were cut into small pieces ( $8 \mathrm{~mm}$ square), inoculated with A. tumefaciens in dilute overnight culture medium $\left(\mathrm{OD}_{630}=0.25\right)$, and blotted dry with sterile filter paper. The explants were placed on MS agar medium containing $40 \mathrm{mg} / \mathrm{L}$ acetosyringone for 3 days and transferred to MS agar medium containing $1 \mathrm{mg} / \mathrm{L}$ benzyladenine, $0.1 \mathrm{mg} / \mathrm{L}$ naphthaleneacetic acid, $500 \mathrm{mg} / \mathrm{L}$ carbenicillin, and $200 \mathrm{mg} / \mathrm{L}$ kanamycin. After 1 month of cultivation, calluses were separated from the leaf segments and subcultured on the 
same medium. After 1 month of cultivation, regenerated shoots were separated from the calluses and transferred to hormone-free MS agar medium containing $200 \mathrm{mg} / \mathrm{L}$ cefotaxim. Transgenic plants that rooted normally were propagated in vitro for DNA analysis. The single-copy transgenic line $(\operatorname{cod} 23)$ was selected on the basis of genetic and Southern blot analysis (Fig. 2). The T0 transgenic line $(\operatorname{cod} 23)$ was self-crossed to produce $\mathrm{T} 1$ transgenic lines $(\operatorname{cod} 23 \mathrm{~A}, \mathrm{~B})$ with a single copy of a target cassette in heterozygous and homozygous conditions. The segregation of kanamycin resistance in their progeny (T2) was investigated to identify their copy number of target cassettes.

Leaf segments of in vitro clones of transgenic plant lines $(\operatorname{cod} 23 \mathrm{~A}, \mathrm{~B})$ were inoculated with A. tumefaciens containing p2nd30. The explants were placed on MS agar medium containing $40 \mathrm{mg} / \mathrm{L}$ acetosyringone for 3 days and cultured on MS agar medium containing $1 \mathrm{mg} / \mathrm{L}$ benzyladenine, $0.1 \mathrm{mg} / \mathrm{L}$ naphthaleneacetic acid, and $500 \mathrm{mg} / \mathrm{L}$ carbenicillin for 2 weeks. The explants were then transferred to MS agar medium containing $1 \mathrm{mg} / \mathrm{L}$ benzyladenine, $0.1 \mathrm{mg} / \mathrm{L}$ naphthaleneacetic acid, $500 \mathrm{mg} / \mathrm{L}$ carbenicillin, and $200 \mathrm{mg} / \mathrm{L} \mathrm{5-fluorocytosine.} \mathrm{After} 1$ month of cultivation, calluses were separated from the leaf segments and subcultured on the same medium. After 1 month of cultivation, regenerated shoots were separated from the calluses and transferred to hormone-free MS agar medium containing $200 \mathrm{mg} / \mathrm{L}$ cefotaxim. Transgenic plants that rooted normally were propagated in vitro for DNA analysis.

PCR and Southern analysis

Genomic DNA was isolated from leaves of in vitro transgenic plants using a FastDNA Kit, following the supplier's instructions (Bio 101, Qbiogene, Carlsbad, CA, USA). PCR was carried out under standard conditions with 30 cycles of $30 \mathrm{~s}$ of denaturation at $94{ }^{\circ} \mathrm{C}, 30 \mathrm{~s}$ of annealing at $60^{\circ} \mathrm{C}$, and $2 \mathrm{~min}$ of extension at $72{ }^{\circ} \mathrm{C}$. Reaction products were resolved by electrophoresis on $1.2 \%(\mathrm{w} / \mathrm{v})$ agarose gel. The sequences of the PCR primers (Fig. 1) were as follows:

SPR3: $\quad$ 5'-TTACTTTGCGTTTGTGTACT-3'; SPL3: $\quad 5^{\prime}$-TGCTTTTGCGTCTGCCATTG-3';
Luc3: $\quad$ 5'-CGTTCGGTTGGCAGAAGCTATG AAA- $3^{\prime}$;

Luc8a: $\quad$ 5'-TTTCATAGCTTCTGCCAACCGA ACG-3'.

Genomic DNA was isolated from leaves of in vitro transgenic plants by a modified CTAB method. Ten micrograms of DNA were digested with appropriate restriction enzymes, separated on $0.8 \%$ (w/v) agarose gel and blotted onto a nylon membrane (Hybond-N, Amersham). After UV crosslinking, the membrane was hybridized with a DIG-labeled probe. The probe DNA fragment was labeled by PCR using DIG-dUTP, following the supplier's instructions (Boehringer Mannheim). PCR primers for labeling were as follows:

P1 probe: 5'-TAACGCTTTACAAACAATTA-3' and $5^{\prime}$-CGCCCCGTTATAGGAGTGC A- $3^{\prime}$;

P2 probe: $\quad 5^{\prime}$-ACATAAGATGATACGCAAG $\mathrm{C}-3^{\prime}$ and $5^{\prime}$-CATTGCGGACGTTTTTAAT GTACTG-3';

P3 probe: 5'-GTTTACCCGCCAATATACCTG TCA-3' and $5^{\prime}$-TCATGTGTTTGCGTTTCA TT- $3^{\prime}$;

P4 probe: $\quad 5^{\prime}$-CATCACGGTTTTGGAATGTTT ACTA- $3^{\prime}$ and 5'-CGGAGGATTACAATAGCT AAGAATT- $3^{\prime}$;

P5 probe: 5'-CGTTCGGTTGGCAGAAGCTAT GAAA- $3^{\prime}$

and $5^{\prime}$-AGGTGCGCCCCCAGAAGC AATTCG-3'

Hybridization, washing, and detection were performed using DIG Easy Hyb (hybridization solution) and a DIG Wash and Block Buffer Set (Roche, Penzberg, Germany) following the supplier's instructions.

Luciferase assay

Luciferase activity was assayed in five expanded leaf extracts after undergoing the various treatments described using the Pica Gene luciferase assay kit (Toyo-Inc., Tokyo, Japan). The protein concentration 
of the extract was determined using the Bio-Rad Protein Assay kit (Bio-Rad, Hercules, CA, USA). The light intensity from $1 \mu \mathrm{g}$ of the protein extract was measured using a Luminescenser-JNR (ATTO, Tokyo, Japan) for $10 \mathrm{~s}$, and is represented as the relative luciferase activity (RLA/ $\mu \mathrm{g})$.

Acknowledgments This work was supported by NEDO (New Energy and Industrial Technology Organization) and RITE (Research Institute of Innovative Technology for the Earth).

Open Access This article is distributed under the terms of the Creative Commons Attribution License which permits any use, distribution, and reproduction in any medium, provided the original author(s) and the source are credited.

\section{References}

Akiyoshi DE, Klee H, Amasino RM, Nester EW, Gorden MP (1984) T-DNA of Agrobacterium tumefaciens encodes an enzyme of cytokinin biosynthesis. Proc Natl Acad Sci USA 81:5994-5998

Araki H, Nakanishi N, Evans BR, Matsuzaki H, Jayaram M, Oshima Y (1992) Site-specific recombinase, R, encoded by yeast plasmid pSR1. J Mol Biol 225:25-37

Belhaj K, Chaparro-Garcia A, Kamoun S, Nekrasov V (2013) Plant genome editing made easy: targeted mutagenesis in model and crop plants using the CRISPR/Cas system. Plant Methods 9:39

Cai CQ, Doyon Y, Ainley WW, Miller JC, DeKelver RC, Moehle EA, Rock JM, Lee Y-L, Garrison R, Schulenberg L, Blue R, Worden A, Baker L, Faraji F, Zhang L, Holmes MC, Rebar EJ, Collingwood TN, Rubin-Wilson B, Gregory PD, Urnov FD, Petolino JF (2009) Targeted transgene integration in plant cells using designed zinc finger nucleases. Plant Mol Biol 69:699-709

de Pater S, Neuteboom LW, Pinas JE, Hooykaas PJJ, van der Zaal BJ (2009) ZFN-induced mutagenesis and gene-targeting in Arabidopsis through Agrobacterium-mediated floral dip transformation. Plant Biotechnol J 7:821-835

de Pater S, Pinas JE, Hooykaas PJJ, van der Zaal BJ (2013) ZFNmediated gene targeting of the Arabidopsis protoporphyrinogen oxidase gene through Agrobacterium-mediated floral dip transformation. Plant Biotechnol J 11:510-515

Ebinuma H, Sugita K, Endo S, Matsunaga E, Yamada K (2005) Elimination of marker genes from transgenic plants using MAT vector systems. In: Pena L (ed) Methods in molecular biology (vol 286), transgenic plants. Humana Press, NJ, pp 237-253

Ebinuma H, Nanto K, Kasahara S, Komamine A (2012) Markerfree gene targeting by recombinase-mediated cassette exchange (RMCE). In: Dunwell J, Wetten A (eds) Methods in molecular biology 847, transgenic plants, 2nd edn. Springer, New York, pp 379-390

Endo M, Toki S (2014) Toward establishing an efficient and versatile gene targeting system in higher plants. Biocatal Agric Biotechnol 3:2-6
Li Z, Xing A, Moon BP, McCardell RP, Mills K, Falco SC (2009) Site-specific integration of transgenes in soybean via recombinase-mediated DNA cassette exchange. Plant Physiol 151:1087-1095

Li Z, Moon BP, Xing A, Liu ZB, McCardell RP, Damude HG, Falco SC (2010) Stacking multiple transgenes at a selected genomic site via repeated recombinase-mediated DNA cassette exchanges. Plant Physiol 154:622-631

Louwerse JD, van Lier MCM, van Der Steen DM, de Vlaam CMT, Hooykaas PJJ, Vergunst AC (2007) Stable recombinase-mediated cassette exchange in Arabidopsis using Agrobacterium tumefaciens. Plant Physiol 145:1282-1293

Maniatis T, Fritsh E, Sambrook J (1982) Molecular cloning: a laboratory manual. Cold Spring Harbor Laboratory Press, Cold Spring Harbor

Nagel R, Elliot A, Masel A, Birch RG, Manners JM (1990) Electroporation of binary $\mathrm{Ti}$ plasmid vector into Agrobacterium tumefaciens and Agrobacterium rhizogenesis. FEMS Microbiol Lett 67:325-328

Nanto K, Ebinuma H (2008) Marker-free site-specific integration plants. Transgenic Res 17:337-344

Nanto K, Yamada-Watanabe K, Ebinuma H (2005) Agrobacterium-mediated RMCE approach for gene replacement. Plant Biotechnol J 3:203-214

Nanto K, Sato K, Katayama Y, Ebinuma H (2009) Expression of a transgene exchanged by the recombinase-mediated cassette exchange (RMCE) method in plants. Plant Cell Rep 28:777-785

Qi Y, Zhang Y, Zhang F, Baller JA, Cleland SC, Ryu Y, Starker CG, Voytas DF (2013) Increasing frequencies of site-specific mutagenesis and gene targeting in Arabidopsis by manipulating DNA repair pathways. Genome Res 23:547-554

Schlaman HRM, Hooykaas PJJ (1997) Effectiveness of the bacterial gene $\operatorname{cod} A$ encoding cytosine deaminase as a negative selectable marker in Agrobacterium-mediated plant transformation. Plant J 11:1377-1385

Shukla VK, Doyon Y, Miller J, DeKelver RC, Moehle EA, Worden SE, Mitchell JC, Arnold NL, Gopalan S, Meng X, Choi VM, Rock JM, Wu YY, Katabah GE, Zhifang G, McCaskill D, Simpson MA, Blakeslee B, Greenwalt SA, Butler HJ, Hinkley SJ, Zhang L, Rebar EJ, Gregory PD, Urnov FD (2009) Precise genome modification in the crop species Zea mays using zinc-finger nucleases. Nature 459:437-441

Singer K, Shiboleth YM, Li J, Tzfira T (2012) Formation of complex extrachromosomal T-DNA structures in Agrobacterium tumefaciens-infected plants. Plant Physiol 160:511-522

Srivastava V, Ow DW (2004) Marker-free site-specific gene integration in plants. Trends Biotechnol 22:627-629

Tinland B, Hohn B, Puchta H (1994) Agrobacterium tumefaciens transfers single-stranded transferred DNA (T-DNA) into the plant cell nucleus. Proc Natl Acad Sci USA 91:8000-8004

Townsend JA, Wright DA, Winfrey R, Fu F, Maeder ML, Joung JK, Voytas DF (2009) High-frequency modification of plant genes using zinc-finger nucleases. Nature 459:442-445

Turan S, Galla M, Ernst E, Qiao J, Voelkel C, Schiedlmeier B, Zehe C, Bode J (2011) Recombinase-mediated cassette exchange (RMCE): traditional concepts and current challenges. J Mol Biol 407:193-221 
Turan S, Zehe C, Kuehle J, Qiaoc J, Bode J (2013) Recombinase-mediated cassette exchange (RMCE) - a rapidly-expanding toolbox for targeted genomic modifications. Gene 515:1-27

Tzfira T, Weinthal D, Marton I, Zeevi V, Zuker A, Vainstein A (2012) Genome modifications in plant cells by custom-made restriction enzymes. Plant Biotechnol J 10(4):373-389

Wang Y, Yau YY, Perkins-Balding D, Thomson JG (2011) Recombinase technology: applications and possibilities. Plant Cell Rep 30:267-285
Wright DA, Townsend JA, Winfrey RJ Jr, Irwin PA, Rajagopal J, Lonosky PM, Hall BD, Jondle MD, Voytas DF (2005) High-frequency homologous recombination in plants mediated by zinc-finger nucleases. Plant J 44:693-705

Zhang Y, Zhang F, Li C, Baller JA, Qi Y, Starker CG, Bogdanove AJ, Voytas DF (2013) Transcription activator-like effector nucleases enable efficient plant genome engineering. Plant Physiol 161:20-27 